\title{
MODERNIZAÇÃO AGRÍCOLA, PRODUTIVIIDADE ESPACIAL E GUERRA DE MERCADOS, O EXEMPLO DA PATAGÔNIA NORTE (ARGENTINA)
}

\author{
Maria Laura Silveira*
}

Os novos conteúdos técnicos e organizacionais, próprios da fase atual da globalização, transformam crescentes parcelas do espaço. De um meio técnico (Friedman, G., 1977) - correspondente à fase da internacionalização - passamos a um meio técnico-científico-informacional (Santos, 1993). A reorganização do espaço argentino pode, assim, ser compreendida à luz de uma nova divisão territorial do trabalho que exige modernizar objetos e ações.

Dessa maneira, as regiões argentinas destinadas à agricultura são objeto, em face das novas condições do mercado mundial, de uma modernização seletiva a partir da incorporação de técnicas científicas de produção e comercialização. Nesse contexto de refuncionalização produtiva, pretendemos aqui discutir alguns aspectos da cientificização da agricultura na Patagônia Norte.

\section{MODERNIZAÇÃO AGRÍCOLA E GUERRA DE MERCADOS: A PATAGÔNIA NORTE E OS NOVOS PAÍSES PRODUUTORES}

A atividade agrícola da Patagônia Norte (Províncias de Rio Negro e Neuquén), iniciada na segunda década do presente século, especializa-se na produção de maçãs e pêras para exportação e configura, ainda hoje, a área mais importante da produção nacional (mais de uns 70\%) dessas frutas. Esta função regional atingiu sua maior rentabilidade por volta dos anos cinqüenta, no momento em que se registraram altos volumes de exportação de frutas num mercado de escassa concorrência internacional. Os sistemas técnicos que serviram de base a essa produção seguiram os padrões europeus e eram contemporâneos das técnicas mundiais mais avançadas.

Todavia, a partir dos anos sessenta e setenta, a exportação argentina de maçãs e pêras começa a diminuir por causa do envelhecimento dos sistemas de engenharia, o que implica numa menor produtividade e numa mais baixa qualidade se comparada com novas áreas mundiais de produ- ção. Uma outra causa dessa decadência relativa está dada pelo surgimento de novos e importantes países produtores desses tipos de fruta. Com efeito, a África do Sul, o Chile, a Austrália, a Nova Zelândia e, também, aqueles países que foram tradicionalmente mercados argentinos: o Brasil, os Estados Unidos e a Comunidade Econômica Européia, iniciam produções comerciais de maçãs a partir de técnicas e formas organizacionais mais modernas. Estas nações têm obtido, com freqüência, nos últimos anos, uma produtividade mais elevada e uma qualidade superior, ao tempo em que desenvolvem um eficiente processo de comercialização. A partir da seguinte tabela podemos comparar os volumes de produção e exportação dos principais países concorrentes da Argentina:

TABELA N ${ }^{\circ}$ 1: PRODUÇÃO E EXPORTAÇÃO DE MAÇÃS E PÊRAS NOS PAÍSES DO HEMISFÉRIO SUL (EM MILES DE TONELADAS) - 1991.

\begin{tabular}{|l|c|c|c|r|c|}
\hline & Argentina & Chile & Af.do Sul & N.Zelândia & Austrália \\
\hline Produção & & & & & \\
maçãs & 1070 & 730 & 560 & 416 & 350 \\
pêras & 251 & 155 & 195 & 12 & 157 \\
Exportação & & & & & 213,3 \\
maçãs & 230 & 335 & 225 & 26 \\
pêras & 155 & 105 & 87,5 & 1,7 & 37 \\
\hline Fonte: Revista Horticultural Products, extraido de "Noticiero Frutícola" \\
(CAFI), N $\mathrm{N}^{\circ}$ 1701, 15/5/1991.
\end{tabular}

Desse modo, observamos que a economia frutícola argentina não apresenta propriamente uma desaceleração da sua produção - os volumes de produção aparecem mais ou menos constantes graças à expansão das áreas destina-

(*) Professora Assistente na Universidad Nacional del Comahue (Neuquén, Argentina) Doutoranda no Departamento de Geografia da Universidade de São Paulo. 
das às plantações - , mas uma queda relativa da sua vocação exportadora presente nas suas origens. Com efeito, enquanto a Argentina exporta hoje apenas uns $21,5 \%$ da produção nacional de maçãs, o Chile fica com uns 45,9\%, África do Sul $40,2 \%$ e a Nova Zelândia 51,3\%. Contudo, no que se refere ao mercado das pêras, a Argentina exporta uns $61,8 \%$ da sua produção, o Chile $67,8 \%$ e África do Sul 44,9\%, sendo pouco importante a função exportadora dos demais países neste ramo.

O crescimento diferencial da produção desses países revela, entre outras coisas, a incorporação seletiva das técnicas mais modernas. Por outra parte, as disputas por mercados tradicionalmente compradores de maçãs estaria expressando, entre outros vários aspectos, os diferentes graus de eficácia das políticas comerciais, assim como a observância às normas mundiais de qualidade e uso dos pesticidas.

A produção australiana de maçãs aumentou $11 \%$ nesse período graças sobretudo à incorporação da técnica de culturas de alta densidade (360 plantas por hectare), mas também ao impedimento das importações neozelandesas para evitar a propagação do "fogo bacteriano" e à conquista mediante campanhas publicitárias - de mercados sul-asiáticos: Singapura, Hong Kong e Malásia, além de europeus como Alemanha e Finlândia. Em relação à produção de pêras, cujo crescimento foi de uns $3 \%$, existiu um avanço sobre o mercado europeu (Inglaterra, França) e nos Estados Unidos, Singapura e Hong Kong a partir da variedade Nashi ou pêra asiática.

O exemplo chileno revela um aumento de $6 \%$ da produção entre uma colheita e outra, em virtude de uma alta tecnificação e de uma mudança das variedades para adequálas aos exigentes gostos europeus. Isso significou um aperfeiçoamento das variedades Red Delicious exportadas à Comunidade Econômica Européia e Oriente Médio e da Granny Smith aos Estados Unidos. Esta revolução frutícola chilena - iniciada no fim da década de 1970 - introduziu, também, certas espécies que, amadurecendo duas ou três semanas antes, lhe permitem chegar aos mercados mais aceleradamente do que as frutas argentinas.

A produção sulafricana apresenta conhecidas características de alta qualidade que fazem com que mais de $90 \%$ dela seja importada pela Comunidade Econômica Européia.

A Nova Zelândia incrementou sua produção de maçãs em uns $3 \%$ de um ano para outro, sendo seus principais compradores os Estados Unidos e a Europa. Este país encontra-se num processo de substituição de espécies cultivadas com o objetivo de expandir seus mercados.

Além da menor aceleração no crescimento das exportações, a produção argentina apresenta uma dependência histórica de mercados, os quais diminuem as demandas da produção doméstica. Assim, em 1993, uns 55\% das exportações de maçãs foi orientada à Comunidade Econômica Européia, $20 \%$ para o Brasil e o restante $25 \%$ para outros mercados. A tendência quase se reproduz no comércio de pêras: a Europa recebe uns $44 \%$ das exportações argentinas, os Estados Unidos $43 \%$ e o $13 \%$ restante se distribui em outros mercados. A essa estrutura comercial dependente se acrescenta o problema da queda relativa dos preços obtidos pela fruta argentina nos mercados internacionais. O preço da caixa de maçãs de 20 kg. caiu, no mercado de Rotterdam, de 19,26 dólares em 1992 a 14,57 dólares em 1993.

Por outra parte, a produção de maçãs no Brasil, cujo início se situa na década de 1960 , não atinge relevância senão a partir de 1980, sobretudo graças às ações do Estado. Os principais Estados produtores são Santa Catarina, Rio Grande do Sul e Paraná, nos quais as condições climáticas possibilitam o desenvolvimento desse tipo de fruta. Ainda que apresentem a vantagem de não precisar um sistema de irrigação graças à abundância das chuvas, essas plantações enfrentam o problema da "dormancia", por causa das poucas horas de frio, o qual deve ser resolvido via produtos químicos. Os volumes de produção alcançam as 400.000 toneladas anuais, concentrados nas espécies Gala (36\%), Fuji (32\%) e Golden Delicious (20\%), mas, hoje, apenas uns $15 \%$ a $20 \%$ da maçã Gala atingem uma qualidade de exportação. As expectativas de aumentar as exportações são crescentes e, com isso, as tentativas de reduzir o ingresso de fruta argentina baseado em rigorosos controles classificatórios e fitosanitários.

Contribuem para essa guerra de mercados as condições técnicas específicas de cada formação socioespacial quanto seus sistemas organizacionais, sendo essas singularidades o resultado das resistências e das oportunidades que cada lugar oferece à chegada dos vetores da modernidade. Essa seletividade da modernização nos lugares acaba por oferecer retratos diversos e únicos, onde a produtividade e a conquista de mercados interagem dialéticamente.

Todavia, na questão da produtividade espacial, é preciso levar em consideração certas variáveis da história do 
presente a um nível global. Nesse sentido, as imposições dos organismos mundiais e dos países mais desenvolvidos traduzir-se-iam em normas básicas do comércio internacional, em relação às qualidades e quantidades dos produtos, assim como na incorporação das técnicas modernas. Parece-nos que esses dados configurariam os traços definitórios de uma nova divisão territorial do trabalho.

A guisa de exemplo, poderíamos mencionar que a guerra comercial entre esses países ganha novas nuanças a partir das possibilidades oferecidas pelo sistema de atmosfera controlada ULO (Ultra Low Oxigen), que permite controlar, com dispositivos informáticos, os conteúdos de gás, e garantir assim as condições de qualidade da produção armazenada. Essa inovação técnica permitiu ao Chile conquistar os mercados dos países árabes através de envios fora da estação. Não obstante, isso implica em uma queda da demanda daqueles países que, embora produtores, eram obrigados a importar frutas na contra-estação. Esse é o caso das nações européias e, entre elas, da Bélgica que tem uns 30\% dos seus frigoríficos equipados com essa tecnologia. Esses Estados reduzem agora as importações do Hemisfério Sul já que podem contar com suas próprias produções armazenadas $\mathrm{o}$ ano inteiro.

\section{NORMAS MUNDIAIS E NORMAS NACIONAIS: UM FATOR DE REORGANIZAÇÃO DOS MAPAS HISTÓRICOS DE PRODUÇÃO E DEMANDA DE FRUTAS}

A respeito das normas internacionais de qualidade no que concerne às frutas, a Organização das Nações Unidas para a Agricultura e a Alimentação (FAO) e o Departamento de Agricultura dos Estados Unidos (USDA) exigem a observação de uma zonificação, por eles elaborada, de áreas livres da "mosca do Mediterrâneo". Esses organismos do governo mundial estabeleceram autoridades competentes na área fitosanitária que devem certificar essas zonas livres. Assim, os novos sistemas organizacionais impõem mudanças no comércio internacional, a partir da arbitragem sobre a admissão e a permanência dos novos e dos antigos lugares de produção. Tratar-se-ia de uma rehierarquização dos países produtores, uma vez que se estabelecem normativas globais que vão se superpor a um mapa de produções e demandas desenhado num período histórico de internacionalização e de intercâmbios notadamente binacionais. Mas, dessa forma, essas normativas hegemônicas também impulsionam a mundialização dos sistemas técnicos destinados a assegurar essas condições de qualidade, ao tempo em que globalizam a informação técnica e mercadológica. Esse processo revela, portanto, uma lógica contraditória de homogeneização e fragmentação da economia e do território mundiais.

No exemplo anteriormente citado, observamos que o estabelecimento de controles fitosanitários, enquanto condiciona e redesenha os fluxos de exportação e importação de frutas, impõe o uso ou desuso de certos produtos da agroquímica e, por conseguinte, modifica a estrutura do mercado dos insumos e a balança de pagamento dos países envolvidos. Existem regulamentações e procedimentos internacionais, conforme registros de tolerâncias de praguicidas, para aceitar as importações de frutas.

Por isso, este esquema regulatório internacional seria uma nova modalidade de difusão de inovações técnicas e organizacionais e, ao mesmo tempo, de prescrever o envelhecimento das inovações anteriores. Um mercado globalizado passa a dominar, hoje, o tipo de produção e a forma de realizá-la, e a não observância dessas normas, por parte dos países exportadores, pressupõe, não raro, o risco de perder mercados essenciais.

Essas políticas globais obrigam a um país como Argentina, tradicionalmente produtor de maçãs e pêras mas, hoje, com escassa velocidade de renovação técnica e organizacional, a criar organismos de controle para dar conta das exigências do mercado internacional. Em consequiência, em 1991, cria-se o IASCAV (Instituto Autárquico responsável pela sanidade e qualidade da fruta que ingressa e egressa do país) para controlar as condições fitosanitárias da produção segundo as exigências vigorantes, e também para cumprir a função de interlocutor com os organismos internacionais. Essa recente fiscalização interna surge como uma forma de assegurar a fluidez do comércio internacional e contribui para uma nova organização do território.

Não obstante, a criação de instâncias nacionais conforme os imperativos mundiais, não é suficiente, hoje, para garantir a continuidade das vendas no mercado europeu. A partir de 1993, a Comunidade Econômica Européia exige, para autorizar a entrada da fruta, um "atestado de conformidade" que é entregue pelos técnicos dos organismos oficiais europeus encarregados de revisar as frutas em seu destino. Esses diferentes controles parecem significar novas instâncias de disputa entre os países fornecedores do mercado europeu. 


\section{PRODUTIVIDADE ESPACIAL:UMA PERSPECTIVA DA GUERRADOSMERCADOS}

A modernização seletiva se reconhece nos novos objetos técnicos e nas idéias e normas exigidas para seu funcionamento, o que define cada lugar. Esse processo de modernização dos lugares implica em um diferente grau de aptidão para a produção de um certo produto, em uma menor viscosidade nas relações com o mercado mundial e, por conseguinte, em uma melhor oportunidade para obter rentabilidades crescentes. Esse conjunto de dados técnicos e políticos que cada lugar oferece pode ser definido como a produtividade espacial. (Santos, 1993)

Segundo Roberto Lobato Corrêa, "as novas especializações produtivas, tanto rurais como urbanas, resultantes de novos padrões locacionais relevantes para a acumulação capitalista, vão traduzir-se na recriação das diferenças espaciais. Diferenças de custos da força de trabalho, na distribuição dos recursos naturais, da infra-estrutura e dos mercados consumidores são fatores que afetam as novas localizações geradoras, por sua vez, de novos padrões de interações espaciais."(1993: 144).

De tal modo, a guerra de mercados, no que se refere ao comércio de frutas, significa uma concorrência de regiões diferencialmente dotadas de objetos técnicos e organizações modernas que definem a sua produtividade espacial.

Por isso, a situação atual de decadência relativa das regiões produtoras de frutas da Argentina, se comparada com outras regiões produtoras do mundo, estaria dando origem a um processo de modernização dos sistemas técnicos e dos sistemas de ações, que busca aumentar a produtividade espacial de modo a concorrer em melhores condições no mercado mundial.

\section{UMAREHERARQUIZAÇÃOPRODUTIVADOS LUGARESNA AGRICULTURADA PATAGÔNIA NORTE?}

Como se reorganiza a atividade agrícola na Patagônia Norte em face destas novas exigências internacionais de produção e exportação? Qual seria a produtividade espacial para a produção de maçãs e pêras nas antigas e nas novas áreas agrícolas da Patagônia Norte?

A heterogeneidade da modernização aparece como um dado relevante na difusão do meio técnico-científico, criando e recriando verdadeiras "zonas luminosas" e "zonas opacas" (Santos, 1993:4) numa diferente hierarquização produtiva dos lugares. Diante das atuais exigências de produção e exportação, do jogo contraditório entre políticas protecionistas e doutrinas de livre mercado, dos riscos de perda de mercados, a transformação dos espaços produtivos se impõe. Este processo de transformação concretizase a partir da incorporação de conteúdos científicos e técnicos à produção, à comercialização e à distribuição, assim como de novas ações modificatórias das condições organizacionais e políticas do trabalho. Contudo, essa modernização, fazendo-se de maneira seletiva, nos autoriza a distinguir entre lugares mais e menos luminosos, dinâmicos, modernos.

Em conseqüência, na região da Patagônia Norte, as tendências do período atual podem ser reconhecidas, entre outras formas geográficas, nas diferentes zonas de produção agrícola. Dois subespaços se salientam na produção frutícola: o "Alto Valle de Río Negro y Neuquén" e o "Valle Medio de Río Negro". O primeiro configura a zona mais antiga de ocupação agrícola intensiva cujo envelhecimento dos sistemas de engenharia contribui, certamente, para trazer-lhe problemas de competitividade mundial. Por outra parte, o Vale Médio tem sido recentemente destinado para a produção de frutas para exportação, com a incorporação de técnicas de última geração tais como clones para obter árvores anãs e frutos maduros antecipadamente a outros lugares de produção, sistemas informatizados de irrigação, adubo, determinação de graus de temperatura e umidade, sistemas de refrigeração de atmosfera controlada com tecnologia computadorizada, etc. Uma rápida incorporação de modernas famílias de técnicas, hoje utilizadas na Europa, em particular na Itália, nos Estados Unidos e no Japão, junto ao extraordinário avanço da fronteira agrícola (em 1992 se preparavam 8 a 10 hectares por dia) refletem, entre outras coisas, a necessidade de melhorar os sistemas de engenharia para concorrer com os novos países exportadores, notadamente aqueles do Hemisfério Sul.

Ainda que o Vale Médio supere o Vale Alto em condições tais como o tamanho dos terrenos (entre 100 e 1000 hectares, quando no Vale Alto dificilmente chegam a 100 hectares) que tornam mais rentável a exploração, os sistemas de engenharia apresentam algumas carências, como é o caso da não terminação das obras da usina convertedora de energia (estação Pomona, dependente de Hidronor). A disponibilidade de terras livres com infra-estrutura para irriga- 
ção era de 43\% no Vale Médio em 1988, enquanto no Vale Alto era de apenas $16 \%$. Estes dados revelam que a modernização na segunda zona só pode ser feita a partir da reconversão dos sistemas de engenharia existentes e não tanto com a incorporação de áreas novas. Nesse sentido, a utilização da técnica de cultura "em espaldera", que permite a introdução de 460 plantas por hectare, é maciça na nova área, enquanto no Vale Alto ainda uns $57 \%$ da superfície cultivada corresponde à técnica chamada de "monte tradicional" (180 plantas por hectare). Além disso, esta área caracterizase pela existência de plantas envelhecidas e de espécies de grande tamanho que demoram muitos anos para atingir a produção plena. Também as técnicas de defesa contra geadas revelam um processo de modernização seletiva: irrigação por aspersão no Vale Médio e nas plantações mais modernas do Vale Alto que contrastam com a ineficiente e antiga prática da queima de pneus para proteger as plantas.

Apesar da utilização das técnicas de última geração que tornam - tendencialmente - mais produtiva a nova área de produção frutícola, as quantidades obtidas não conseguem ainda igualar aquelas da África do Sul. Efetivamente, enquanto na Argentina se produzem $15.000 \mathrm{~kg}$./hectare, naquele país os rendimentos alcançam $25.000 \mathrm{~kg}$./hectare.

Ainda que novas ações venham modificar certas condições do trabalho e da produção, antigos sistemas organizacionais permanecem e, desse modo, reduzem a produtividade espacial dos vales agrícolas. Por exemplo, no Chile, o produtor recebe um pagamento só pela caixa de fruta com qualidade de exportação, enquanto não é aceita aquela caixa que apresenta uma qualidade insatisfatória. Pelo contrário, na Argentina, o pagamento é efetuado pelo kilograma de fruta, o qual tem um preço baixo porque é único para toda a produção. De tal modo que a seleção da fruta para exportação é posterior à fixação do preço único.

Entre as mais recentes modalidades de organização empresarial, poderíamos mencionar a formação de grupos de produtores integrados. Trata-se de grandes empresas que se associam a produtores pequenos e médios - com explorações eficientes, mas sem capacidade de manterem-se independentes no mercado - e lhes exigem certos níveis de qualidade e custos.

Esta ocupação do Vale Médio é realizada pelas firmas mais importantes da região: Zetone y Sabbag, Moño Azul, Kleppe, Expofrut, Mc Donald, entre outras. Esses grupos investem, ao mesmo tempo, na modernização tecnológica do
Vale Alto. Contudo, nesta última área, as técnicas de produção e organização - que datam de 1940 e 1950 - obstaculizam o processo de renovação porque determinam um funcionamento diverso, talvez menos eficiente, das novas inovações incorporadas. Em decorrência, no Vale Alto existe ainda uma grande heterogeneidade de maquinárias, instalações e sistemas de trabalho distribuidos em mais de 250 empresas, sendo a maior parte delas de escassa capacidade para reciclar técnicas e organizações. A modernização aparece, então, como a cara visível de um processo menos explícito de forte concentração do capital e das terras.

\section{O ESTADO E SEUS NOVOS PAPÉIS CONTRIBUINDO PARA UMA MAIOR PRODUTIVIDADE ESPACIAL}

Essa modernização seletiva, em ambos os vales agrícolas, é promovida, também, pelos caudais de informação. Os agentes hegemônicos e o Estado se inserem em redes informacionais sobre marketing, técnicas, preferências globais. Assim, o Estado cria centros de pesquisa, institutos e organismos que estabelecem sistemas de aperfeiçoamento e difusão de técnicas de produção e de organização de mercado. Um terciário altamente qualificado desenvolve um trabalho cada vez mais intelectualizado que antecede à produção material. O Instituto Nacional de Tecnologia Agropecuária (INTA), por exemplo, organiza intensas campanhas informativas (cursos, seminários, conferências, documentos e publicações) sobre técnicas modernas de cultivo, de irrigação e adubo, novas espécies, mudanças nos hábitos de consumo dos principais países compradores, conjuntamente com planos de qualificação profissional destinados, especialmente, aos níveis de gestão técnica das firmas.

Por outra parte, no que se refere à difusão das técnicas de organização da produção material, poderíamos mencionar o estabelecimento por parte do Estado de um cronograma - que conduziria a uma crescente organização centralizada da produção - chamado "Programa de madurez". Este cronograma determina as datas das colheitas segundo as variedades e os lugares. Estaríamos assistindo à progressiva substituição de antigos padrões empírico-cotidianos de organização temporal e ritmos de trabalho agrícola por novos cronogramas que introduzem uma exatidão científica.

Como a cientificização da agricultura exige qualificação da mão-de-obra e difusão de informações, com freqüência, é o Estado quem assume essa tarefa e destina parcelas 
do seu orçamento para a orientação dos mais importantes exportadores.

Além das ações orientadas a aumentar a circulação de informações, o Estado - nos seus níveis nacional, provincial e municipal - procura criar e modernizar as infraestruturas. Cabe mencionar aqui as obras de remodelação do porto regional de San Antonio Este - através do qual se exporta hoje uma grande parte da produção local - a instalação de alfândegas provinciais e de mercados concentradores da produção na região, o melhoramento das estradas e das infraestruturas urbanas, o estabelecimento de estações meteorológicas especializadas, entre outros. Por outra parte, créditos públicos permitem aos agentes privados melhorar as suas condições técnicas de produção, circulação e distribuição, em especial a partir das normativas de créditos subsidiados e de fundo de consórcios (dec.991/93 e res.195/93 respectivamente).

Outra função dos sistemas públicos de ações, de fundamental importância em nossos dias, é a mediação política entre os empresários e os sindicatos. Como a cadeia de produção inclui diversas instâncias, são vários os agrupamentos de trabalhadores e, portanto, diversos os reclamos. Em termos políticos, a produtividade espacial é consideravelmente menor que o caso chileno, onde a revolução frutícola começou nos anos do governo ditatorial. Nesse sentido, segundo cálculos de consultores desse país, os custos de trabalho argentinos eram superiores aos chilenos em uns $30 \%$, embora inferiores aos americanos. Não obstante, esse entorno político, caracterizado por uma maior combatividade dos trabalhadores, se modifica com a entrada em vigor do que se chamou de "Pacto Fiscal" (dec. 2609/92) que diminui em uns 50\% os custos de trabalho, a partir da rebaixa das obrigações patronais. Além disso, as novas normas do mercado de trabalho exigem a negociação dos salários por produtividade (dec. 1334/91) e a negociação de trabalho com o empregador (dec. 470/93), evitando em ambas as situações a intermediação dos sindicatos.

Outras normas fiscais merecem ser consideradas na questão da busca de uma maior produtividade espacial. Em relação ao comércio exterior, existe uma desregulação desse comércio (dec. 2284/91), a admissão temporária de insumos, a compensação às exportações (5\% para frutas e $15 \%$ para embalagens), um reembolso por exportação via portos patagônicos, a desregulação portuária (o custo da estiva diminuiu em uns $40 \%$ no porto de San Antonio Este) e a liberação do registro de transportes internacionais (por exemplo, o transporte terrestre para o Brasil baixou em 40\%).

Portanto, esse processo de globalização de produções e mercados obriga o Estado a abandonar funções até agora tradicionais e a desenvolver novos papéis: construção e modernização dos sistemas de objetos, aprovação de normas e leis relativas às relações de trabalho, de produção e de circulação, estabelecimento de redes de informação e crédito que possibilitem um comando da produção à distância e uma organização que anteceda à produção e à distribuição material.

\section{GUERRADEMERCADOS,PRODUTIVDADE ESPACIAL EMODERNIDADEAGRÍCOLANA PATAGÔNIANORTE: UM COMENTÁRIO FINAL}

Novas formas de produção e circulação junto às atuais exigências e funções exportadoras (Silveira, 1993) confluem para desenhar lugares dinâmicos e lugares letárgicos a partir de diferentes conteúdos de produtividade espacial. Os lugares desenvolvem uma disputa à escala regional, nacional e mundial, que é comandada por capitais de variada origem na busca acelerada de maiores rentabilidades em um mercado altamente competitivo.

Um lugar mais letárgico, o Vale Alto, hoje submetido a um processo de modernização, expressa os tempos de entrada da região e do país a um mercado internacional menos competitivo, a partir de um meio técnico moderno que oferecia vantagens comparativas. Os vestígios desse meio técnico, e a produção dele decorrente, testemunha a desaceleração do país na guerra dos mercados, já que a sua produtividade espacial não pode concorrer eficientemente com as produções de lugares dinâmicos organizados pelas tendências do atual meio técnico-científico.

Todavia, essa perda de competitividade da formação socioespacial nacional, no mercado mundial de frutas, encontra-se relativizada pelo recente arranjo de uma área mais moderna de produção. Com efeito, o Vale Médio representaria a organização de uma zona agrícola de alta produtividade espacial do meio técnico-científico, na qual as exigências mundiais se traduzem na precedência do trabalho intelectual que assegura a publicidade, a qualidade, a sanidade, as quantidades a serem comercializadas, com ênfase na aceleração da circulação e da distribuição. Tudo isso regido por 
normas nacionais e mundiais muito rigorosas que configuram um complexo tecido de redes sobre um cenário de disputa de mercados.

Sem embargo, a imposição dessas normas globais junto à busca da supremacia na guerra dos mercados faz com que se criem importantes lugares luminosos no interior do Vale Alto, a partir da reorganização dos seus sistemas técnicos. Esse processo concretiza-se uma vez que os agentes hegemônicos são os mesmos em ambos os subespaços, disputando notadamente com os demais produtores do $\mathrm{He}$ misfério Sul os mercados europeu e brasileiro, graças a um melhoramento da qualidade, a um aumento da variedade e à aceleração da circulação dos produtos.

\section{ABSTRACT}

This paper is an effort to discuss the reorganization of patagonic agriculture (Argentine) and space under the present modernization of objects and actions. New technical contents, changing organizational rules, characteristic of the present globalization period, and leads to the transformation of growing parts of geographical space.

Nowadays, the agricultural production of North of Patagônia - specialized in apples and pears - competes with Southafrican, Chilean, Australian, New Zealander, Brazilian, American and European production. Competitiveness is an important factor of modernization for each country, with different geographic consequences. In the Argentinean (patagonic) case, we have, at least, two trends. On the one hand, heterogeneous modernization with different contents in spatial productivity creates "luminous" and "opaque" zones, dynamic and lethargic places, within a real productive hierarchy of places. On the other hand, the same globalization process of production and market is accompagnied by new state functions creating new circulation forms which facilitate a telecommand production and distribution, strengthening the role of bigger firms.

\section{BIBLIOGRAFIA}

BOSQUE MAUREL, Joaquín. "Nuevas Tecnologías. Crecimiento demográfico y revolución urbana". In: AA.V.V. En el Umbral del Tercer Milenio, Madrid, Expo 1992, pp.321-328.

CHARVET, Jean-Paul. "Organisation de l'espace mondial et flux internationaux de céréales". In: Annales de Géographie., n" 558, Paris, 1991, pp. 166-189.

DEMANGEAT, Daniel. "Les effets géographiques de l'adoption et de la diffusion des technologies nouvelles - L'approche par l'entreprise-". In: Notes de Recherche $N^{\circ} 14$, CRIACentre de Recherche sur l'Industrie et l'Aménagement, Institut de Géographie (Paris I), Paris, 1989.

DIAS, Leila C. "Redes de informação, grandes organizações e ritmos de modernização." In: Anais $3^{\circ}$ Simpósio Nacional de Geografia Urbana, Rio de Janeiro, 1993.

FRIEDMANN, Georges. Sept études sur l'homme et la technique. Denoel/Gonthier, Paris, 1966.
Jornal "Río Negro", General Roca, Argentina, 1992-1993.

Jornal "La Mañana del Sur", Neuquén, Argentina, 1993.

LOBATO CORRÊA, Roberto. "Corporação e Espaço - Uma Nota". R. Bras. Geogr., Rio de Janeiro, 53 (1): 137-145, jan./mar. 1991.

MAMIGONIAN, Armen. "Tecnologia e Desenvolvimento desigual no Centro do Sistema Capitalista." In: Revista de Ciências Humanas, $n^{\circ} 2$, Ed. UFSC, 1982.

SANTOS, Milton. Espaço e Método. Nobel, São Paulo, 1988.

SANTOS, Milton. "Les Espaces de la Globalisation". In: Analyse du Système monde et de l'Économic mondialc, GEMDEV, Paris, février 1993.

SILVEIRA, M.L. "Escalas de tempo simultâneas: o Estado Provincial como agente modernizador do subespaço norpatagônico (República Argentina)". 45ª Reunião Anual da SBPC, Recife, 1993. 